\title{
480 minutos de trabajo por 15 minutos de ocio
}

\author{
Mabir Lubieth Reyes Rivera* \\ Recibido: Agosto 19 de 2014 - Evaluado: octubre 12 de 2014
}

Aceptado: noviembre 10 de 2014

\section{Resumen}

Desde mucho antes de la época conocida como Revolución Industrial, existían trabajadores asalariados que cumplían horarios y vendían su fuerza de trabajo. De la misma manera se evidencia en la historia escrita las diversas luchas obreras que surgen a partir de la indignación de éste gremio por falta de condiciones dignas, aumento salarial y tiempo libre que aunque, no producía remuneración alguna, sí se sentía como necesario para la recuperación física y mental luego de las largas jornadas de trabajo.

En nuestra época, el trabajador asalariado y operario, luego de años de lucha, no obtiene ese tiempo de ocio que ayude a su recuperación emocional, física y mental. En éste punto, empieza a hacerse visible que las limitaciones no son solo las generadas por los empleadores o del sistema (aunque definitivamente el modelo capitalista industrializado se instaló con intenciones de no irse nunca), sino también las creadas por el mismo empleado, que no concibe aún la importancia de un tiempo de ocio por encima del trabajo, de la producción y del mismo dinero.

El texto se divide en tres partes: la primera, dedicada al proceso de lucha obrera de la revolución industrial, que reconoce las razones del origen

"Estudiante de VIII semestre de la Licenciatura en Recreación de la Universidad Pedagógica Nacional. Participé como conferencista en el encuentro EXPOMOTRICIDAD 2013 en Medellín con mi trabajo: El ocio en el trabajador: una lucha obrera que posibilita la mirada al tipo de desarrollo social y humano. Monitora por cuarta vez de la Revista Lúdica Pedagógica, perteneciente a la Facultad de Educación Física de la Universidad pedagógica Nacional. Correo: hegans@gmail.com 
de la indignación demostrada por los trabajadores; la segunda, se dedica a la mirada de otros autores y estudiosos del ocio que se han enamorado de ésta visión de desarrollo humano y la última parte denota una idea de investigación con una población operaria en la actualidad.

Palabras clave: Ocio, trabajo, operario, jornada laboral, tiempo libre. 


\section{MINUTES OF WORK FOR 15 MINUTES OF LEISURE}

\section{Abstract}

Long before the era known as the Industrial Revolution, there were salaried workers who met schedules and sold their workforce. In the same way it is evidenced in written history the various workers' struggles that arise from the indignation of this union for lack of decent conditions, higher wages and time off which, although they did not generate any remuneration, they did felt as necessary to physically and mentally recover after working long hours.

In our time, the salaried employee and worker, after years of struggle, do not obtain the leisure time to help in its emotional, physical and mental recovery. At this point, it begins to become visible that the limitations are not only generated by the employers or system (although definitely the industrialized capitalist model was installed with the intention of never leaving), but also created by the employee itself, who does not yet see the importance of leisure time over work, production and money itself.

The paper is divided into three parts: the first one, dedicated to the process of workers' struggle of the industrial revolution, which recognizes the reasons for the origin of the indignation shown by workers; the second one, dedicated to the view of other authors and scholars of leisure who have fallen in love with this vision of human development and the last part denotes a research idea with a worker population today.

Keywords: Leisure, work, worker, working hours, time off. 


\section{Introducción}

En el transcurso del tiempo a partir de la Revolución Industrial, se ha evidenciado una importante necesidad de identificar espacios de tiempo para los trabajadores operarios en donde puedan liberarse de las tensiones que el trabajo les genera. A este tiempo se le ha identificado, a partir de constantes luchas obreras- lideradas por los trabajadores obreros desde la época mencionada hasta la actual- de distintas maneras como vacaciones pagas, jornadas de trabajo reducidas o domingo de descanso, pero muchos pensadores a través de éstas historias huelguísticas, se han atrevido a hablar del ocio y su relación con el tiempo libre controlado por el mismo sistema industrial que emplea a estos trabajadores.

Esta historia está escrita y permite acercarse al origen de la intención del mantenimiento de un sistema laboral como el industrializado, coartando en sus trabajadores la concepción de un tiempo de ocio, posibilitador de mejores condiciones de vida.

Existen en nuestra cultura educativa, muy pocas evidencias sobre una apuesta equilibrada entre lo que podrían aportar el ocio y el trabajo al desarrollo de un país. Las problemáticas que podrían surgir de este planteamiento son innumerables, sin embargo, para este trabajo, se tratará de focalizar dos, que se presentarán en forma de preguntas.

¿Podría el trabajador-operario hacer uso de un tiempo libre, intrínseco y espontáneo, que reconocemos ahora como ocio, haciendo parte del sistema laboral que rige a la producción masiva y en cadena? y ¿es posible la educación para el ocio en los trabajadores-operarios de un país que educa para el trabajo?

\section{Un poco del trabajo y su reconocimiento en la revolución industrial}

El trabajo es y ha sido un acto reconocido por la humanidad, que se realiza con el fin de recibir una remuneración a cambio; se propone partir de la definición del Diccionario de la Real Academia Española: "Trabajo: ocupación retribuida.”, o remunerada, que significa la recepción de dinero por un trabajo físico o mental que se realiza. 
Existen variadísimas categorías del trabajo, son tipos o clases que se diferencian por sueldo, rango, esfuerzo mental o físico, etc. Cada cual tiene características distintas y aquí se notará que la orientación va más hacia un trabajador que da continuidad a una parte de la historia que ha marcado el sistema económico, laboral y de producción durante años, de todos aquellos países que fueron tocados por la Revolución Industrial. Un trabajador que continúa haciendo parte de la producción masiva, del trabajo fabril, repetitivo y considerablemente mal pagado. Este trabajador se llama operario, producto de un cambio de nombre en la época de la revolución industrial; desde mediados del siglo XVIII hasta mediados del siglo XIX, era reconocido como clase social proletaria o trabajadora y su composición etimológica ocasionó que fuera llamado operario. Así, "La palabra obrero viene del latín operaríus (obrero, peón, jornalero, y también, propio del trabajo), que nos da a sí mismo el cultismo operario (...)” y "Operaríus se deriva de la palabra latina opus, operis (obra, trabajo). De la palabra opus y su variante opera, se derivan también opúsculo, obra, ópera, operar, maniobra o huebra" (Etimologías.dechile.net, s.f). Y aunque autores como Archila (2010) incluye dentro del grupo de obreros al sector manufacturero, a la fecha dentro de nuestro código lingüístico en este campo, se reconoce, al tipo de trabajador del que hablaremos en este escrito como operario.

La revolución industrial impactó en primera medida la forma de elaboración de productos para el consumo que para aquel entonces era algo más artesanal. Elizalde y Gomes (2010) exponen un análisis hecho por Marx el cual explica la diferencia entre el modelo de trabajo existente antes de esta revolución y el que llega con esta, nombrándolos él mismo como trabajo concreto y trabajo abstracto:

El trabajo concreto representa una necesidad de realización humana; en cambio, el trabajo abstracto es apenas un medio de subsistencia, garantizado bajo una forma de pago de un salario que genera, potencialmente, un proceso de alienación. Este proceso, también denominado de "extrañamiento", no se vuelve efectivo sólo en el resultado, sino que también va a abarcar al propio acto de producción. (Elizalde y Gomes, 2010, p. 251)

Los trabajadores-obreros comenzaron a evidenciar su inconformismo con las condiciones indignas del trabajo, mediante las primeras luchas; 
Miranda (2006) rescata los inicios de organizaciones sindicales en Estados Unidos a partir de 1791 en Filadelfia con la primera acción a favor del tiempo libre y también resalta la dedicación de estos trabajadores a la hora de luchar por la obtención de la disminución de la jornada laboral, haciendo uso del poco tiempo que les quedaba luego de las largas jornadas, para estudiar la normatividad que luego querrían transformar. Ahora no solo lucharían, a mediados del siglo XIX, por un simple descanso sino por: "la reivindicación de un verdadero tiempo libre... libre también de la necesidad de descansar, con derecho a reservar cada día un poco de tiempo para su propia educación y para mejorarse a sí mismos" (Miranda, 2006, p. 313); o por ejemplo la lucha en Europa con el movimiento "Ludista", descrita por Abendroth (1970), que muestra con la destrucción de la maquinaria (p. 12) o en Colombia con la formación de la UNIO, fundada en 1904 (Archila, 2010, p. 211), donde se habló por primera vez en Bogotá, de la creación de un partido obrero.

Así pues, la jornada laboral en nuestro país, no se diferencia ampliamente de la normatividad laboral en otros países, caracterizada como Jornada Ordinaria de trabajo: "es el tiempo al que se compromete un trabajador, al laborar al servicio de un empleador, dentro de una relación laboral" y "la Jornada Ordinaria de Trabajo Máxima, corresponde a 8 horas diarias, 48 horas a la semana, de forma tal que, una jornada diaria o semanal superior a la ordinaria, supondría trabajo suplementario o de horas extras." ${ }^{1}$ Esto genera un atisbo de los resultados de luchas obreras en los siglos anteriores, y entonces podría generarse la pregunta de si, ¿el trabajador operario goza de tiempo de ocio o por lo menos lo concibe?

Es preciso ahora sumergirse en el contexto del ocio, que se centrará un poco en la problemática sugerida para éste proyecto.

1 Tomado de la página virtual del Ministerio del Trabajo; véase: http://www.mintrabajo. gov.co/preguntas-frecuentes/jornada-de-trabajo.html 


\section{El ocio y su reconocimiento}

El ocio, sumergido en infinidad de miradas, concepciones y orientaciones desde hace muchos años, es en efecto una palabra sujeta a múltiples discusiones desde épocas muy antiguas.

Se inicia entonces con el significado etimológico de la palabra ocio. Según Hernández (2012) Indica que el ocio en Roma, surge del latín "Otiumdescanso que implica la liberación de los negocios (...). La negación del otium, es el negotium, es decir, trabajo al que se dedicaban comerciantes y mercaderes." (Ibíd., p. 88), reconocido en Roma más como "eminentemente popular de fiestas y espectáculos que será usado también como arma de propaganda y dominio" (Ibídem.) y en la Grecia Antigua "se expresaba con una polisémica palabra, scholé, que ha derivado nada menos que en nuestra palabra <<escuela>>." (Ibíd., p. 77) e indica que para esta Grecia "representaba ante todo un estado de liberación de la necesidad de trabajar (ascholia), que se convierte en primordial para la búsqueda de la sabiduría y la práctica del mejor modo de vida." (Ibíd., p. 78), recalcando que para esta sociedad el trabajo era desprestigiado.

Ahora, a través del tiempo, esta palabra ha sido víctima de un sinfín de acusaciones que la condenan como inmoral, pues el perder el tiempo, no hacer nada y ser vago, han sido sinónimos de ocio juzgados moralmente. Algunas frases existentes, a través de la historia, de personajes reconocidos muestran la promoción del no ocio, como por ejemplo: "El ocio corrompe el cuerpo humano igual que las aguas quietas" recita el poeta latino Ovidio (43 a. de C.); o ésta de Benjamin Franklin: "La ociosidad camina con tanta lentitud, que todos los vicios la alcanzan" (Frasesmotivación.net, s.f.) ; o de Goethe: "Una vida ociosa es una muerte anticipada" (Akifrases.com, s.f.); o ésta de Francisco de Quevedo: "El ocio es la pérdida del salario" (Ibíd.) , que de alguna manera se relaciona con nuestro tema. De hecho Bertrand Russell comienza su libro, "Elogio de la ociosidad", con un acercamiento a lo que hoy en día sigue enseñándose: "Como casi toda mi generación, fui educado en el espíritu del refrán 'La ociosidad es la madre de todos los vicios'. Niño profundamente virtuoso, creí todo cuanto me dijeron, y adquirí una conciencia que me ha hecho trabajar intensamente hasta el momento actual."(1932, s.p.).

El ocio pasó de ser un símbolo de la contemplación, de: "mirar el mundo y lo que nos rodea y disfrutar de su belleza sin pretender imponerle nada" 
(Rul-lán, 1997, p. 174)- que era como se veía en la Grecia clásica-, a un acto por debajo del trabajo con la llegada del cristianismo, que: "supuso una revolución en los conceptos de contemplación y trabajo, dando un paso enorme a la valorización de la acción (del negocio)- que es considerado como la negación del ocio- en detrimento, a largo plazo, de la contemplación (del ocio).”(Ibíd., p. 177), y luego con más fuerza, a la llegada del Renacimiento, donde: "la grandeza del hombre, está en su capacidad para descubrir las causas de lo que ve y su habilidad para someterlo. No se contempla la naturaleza, se la mira y se la examina para poderla dominar con el trabajo [ ].” (Ibíd., p. 180)

Pero así mismo como el ocio ha sido víctima de acusaciones morales durante años, ha sido acogido por estudiosos como éste último y otros que lo conciben como una posible transformación social, por ejemplo Joffre Dumazedier indica que el ocio es: "un conjunto de ocupaciones a las que puede entregarse a su antojo, sea para descansar, para divertirse, desarrollar su información o su formación desinteresada, su participación social, voluntaria tras haberse liberado de sus obligaciones profesionales, familiares y sociales" (citado por Miranda, 2006, p. 303). Miranda (2006) también piensa el ocio como:

(...) un vehículo indispensable para el descanso, sin el ocio no habría recuperación de la fatiga física o nerviosa, de aquí que, el descanso significa reposo y liberación: un reposo reparador por la acumulación de las tensiones de una jornada de trabajo. (...) Ocio y diversión buscan placer y bienestar, encontrarse a gusto, vivir de acuerdo consigo. El desarrollo actual del ocio entraña la reaparición de esta moral del placer. Placer rechazado por varios siglos por la moral del trabajo y los valores sociales. (p. 304)

Ahora los escritores brasileños Elizalde y Gomes en su artículo "Ocio y recreación en América Latina: conceptos, abordajes y posibilidades de resignificación”, acogen al ocio como aquello que el poder siempre ha querido esconder para evitar que el ser humano conozca sus beneficios liberadores y lo expresan majestuosamente en este párrafo:

El ocio puede generar una experiencia de apertura marcada por una actitud que rompa y transgreda con lo permitido y lícito, mostrándose muchas veces al borde de lo socialmente adecuado y aceptado. 
Justamente a esto se debe uno de los grandes temores, así como peligros que representa el ocio para el mantenimiento del status quo. De aquí surge, en parte, el intento de acallar y prohibir la disruptividad, contracorriente, alteridad e innovación subversiva, y todo aquello que pueden expresar un ocio problematizador, caótico, contrahegemónico y transformacional (2010). Con esto, agregamos que el ocio, a su vez puede, permitir el desarrollo de una nueva identidad y de un sentido de pertenencia más abarcador. (Elizalde y Gomes, 2010, p. 11).

Y qué decir de Fernando Tabares con la relación que hace del Desarrollo humano y el desarrollo económico con el ocio, en el capítulo "El ocio y la recreación en América Latina" que dedica al libro "El ocio, el tiempo libre y la recreación en América Latina: problematizaciones y desafíos"; él le aplica a las sociedades "desarrolladas" el seguro que brindan para la aparición del ocio y la recreación "entendida en primera instancia como tiempo libre y acceso a bienes y servicios" (2005, p. 102) y a las "subdesarrolladas", aquellos países que no permiten éstas apariciones por no considerarlas importantes, es decir, "lugares poco propicios para la aparición de éstas prácticas como fenómenos importantes." (Ibíd.)

Y el profesor Manuel Cuenca Cabezas afirma que: "el ocio hay que entenderlo como una experiencia integral de la persona y un derecho humano fundamental. Una experiencia humana (...) centrada en actuaciones queridas, autotélicas (con un fin en sí mismas) y personales.” (Cuenca, 2009, p. 9)

\section{Ocio y jornada laboral}

Si bien la normatividad permite un día de descanso obligatorio, léase bien, "obligatorio, que podrá coincidir con el domingo" ${ }^{2}$, éste no corresponde al tiempo de ocio del que hemos discutido anteriormente, ya por la caracterización de obligado. Por otro lado, los actos que pueden realizarse de manera libre y espontánea con el fin de liberarse por unos minutos de los gajes del trabajo, no corresponde a grandes inversiones de tiempo ni dinero,

2 Tomado de la página virtual del Ministerio del Trabajo; véase: http://www.mintrabajo. gov.co/preguntas-frecuentes/jornada-de-trabajo.html 
tanto para el empleador como para el empleado, sin embargo, para el trabajador operario no es tan fácil tomarse este tiempo mientras sea el único de la "cadena de trabajo" que lo hace, pues la detención de un proceso podría afectar claramente la continuidad del proceso que le sigue, hecho por otro trabajador, por lo que el descanso debe ser en el mismo momento para todos los que hagan parte de esta "cadena de producción".

Pero ¿cuál es el trasfondo real del interés en este escrito por reconocer el tiempo de ocio de éstos trabajadores? ¿Las luchas obreras de la mencionada época industrial verdaderamente consiguieron el tiempo que deseaban y que garantizaba un bienestar real, o simplemente se acogieron a un tiempo libre que les brindaba una sociedad capitalista y consumista?

Bruno Gawriszewski en su artículo publicado en la Revista Digital Educación Física y Deporte de Buenos Aires en el $2003^{3}$ titulado "La lucha capitalista contra el ocio: la necesidad de un ocio consumista", hace que el lector abra los ojos en cuanto al resultado de estas luchas obreras y lo que realmente fue y ha sido ganancia para los que en ese momento eran llamados burgueses. Menciona a la industria del entretenimiento como resultado del "aumento del tiempo libre de los trabajadores”, generado por las gigantescas luchas obreras; señala que:

Henry Ford ${ }^{4}$ encontró una salida: los trabajadores deberían constituirse en consumidores, y por lo tanto sus salarios fueron aumentados sustancialmente, lo cual tuvieron que hacer todos los empresarios. Con el aumento de los salarios, estos nuevos consumidores necesitaban tiempo libre para hacer compras. Entonces, la jornada laboral se redujo para servir a los intereses del capitalismo.

Se ha confundido la orientación del ocio intrínseco, espontáneo, libre y autónomo, al cual se refiere Cuenca, con el consumo excesivo de lo que parece gustarle al ser humano trabajador, que hace uso del tiempo libre controlado

3 Tomado de la web: http://sociologiatl.wordpress.com/2011/03/17/la-lucha-capitalistacontra-el-ocio-la-necesidad-de-un-ocio-consumista/, Publicado en: Educación Física y Deportes Revista digital, Buenos Aires, Año 9 Nro. 66, Noviembre de 2003

4 Recordemos que Henry Ford fue un reconocido empresario millonario del siglo XX impulsador del fordismo que revolucionó la industria. Producción en serie que reducía los costos de fabricación de sus autos para ponerlo al alcance de la "clase media" llevando a esta población a la era del consumo en masa de sus autos. Para saber más de este importantísimo tema, véase: http://www.biografiasyvidas.com/biografia/f/ford_henry.htm 
permitido por la industria, porque lo utiliza en consumir entretenimiento creado por esa misma industria. La educación del ocio no existe, existe la educación para el trabajo y el consumo.

Bien lo describe Gaspar Rul-lán en su artículo "Del ocio al neg-ocio... y otra vez al ocio" ${ }^{5}$ cuando habla de la llegada del protestantismo con Calvino, quien asegura que el número de elegidos por Dios, para salvarse, ya estaba determinado desde la eternidad (...) el éxito en los negocios, se convirtió en signo seguro de predestinación. Dios bendice a los suyos dándoles éxito en su trabajo. Por tanto, cuanto más trabajas, más rico te hacías, y cuanto más rico te hacías más clara era la señal de que Dios te amaba y te había elegido. (...) Con el Calvinismo se dio la vuelta completa y lo que antes era casi despreciado, el negocio, se convirtió en el máximo valor moral, mientras que lo que era exaltado antiguamente, el ocio, se convirtió en el gran pecado. (p. 181)

Definitivamente se está educándo para el trabajo, no para el ocio o ser felices; dice Gaspar:

En este nuestro mundo de mercaderes, lo importante en la educación formal de la escuela y la universidad, o la informal de la familia y la sociedad, es enseñar a negar el ocio, a hacer negocio, produciendo, comprando y vendiendo. Pero, ¿de qué servirán a nuestros jóvenes «tantas idas y venidas, tantas vueltas y revueltas» en el negocio, si al final todos sus esfuerzos terminan en una terrible quiebra de lo único que importa que es la felicidad? (Ibíd., p. 172)

Colombia es uno de los países que conserva esta idea renacentista de la predestinación, que el cielo es para ricos, que el éxito lo tiene aquel con el mejor auto, mejores vestidos y mejor empleo lo cual implica tener más que el otro, "En Colombia se tiene la idea de que el empleado que trabaja los siete días de la semana y hasta que lleva trabajo para su casa, es el mejor" ${ }^{6}$. Esto hace parte del círculo vicioso del consumismo que impide hacer uso de las bondades de la contemplación de las que hablaban los filósofos de la Grecia clásica y que

5 Artículo tomado de la base de datos Dianlet de la Universidad Pedagógica Nacional

6 Describe Carlos Caicedo en un artículo titulado El trabajo flexible se impone a nivel mundial, pero en Colombia tiene sus detractores. Tomado de una de las secciones de la página web actualícese.com 
permitiría observar al mundo más allá de la remuneración que luego será gastada en objetos y servicios vendidos por los mismos dueños de las fábricas y empresas para quienes trabajamos la mayor parte de nuestras vidas. ¿A quién más si no a ellos les interesa vender esa idea renacentista?

\section{La educación en Colombia}

¿Pero de qué manera puede caerse un sistema productivo como este cuando los mismos trabajadores asumen este modelo como algo natural y necesario? Este escrito no puede pasar de largo la mirada al tema del modelo de educación que permite este tipo de pensamiento opositor al tiempo de ocio, favoreciendo el campo del trabajo y al dinero. Puedo comenzar por algunos apartados de artículos de la Ley 115 del 28 de febrero de 1994, que no deja de lado la intención de formar para el trabajo, siendo esta ley promotora en voz alta de la educación técnica y tecnológica, hecha especialmente para la formación del futuro trabajador:

La educación media técnica prepara a los estudiantes para el desempeño laboral en uno de los sectores de producción y de los servicios, y para la continuidad en la educación superior. La educación media técnica está dirigida a la formación calificada en especialidades tales como: agropecuaria, comercio, finanzas, administración, ecología, medio ambiente, industria, informática, minería, salud, recreación, turismo, deporte y las demás que requiera el sector productivo y de servicios. ${ }^{7}$

Artículos como el 5 (numeral 11), el 13 (objetivo g), el 20 (objetivo a), el 27 y el 33 (objetivos a y b), reflejan la intención de una educación básica primaria, básica secundaria y media y una educación técnica, para la formación del trabajo como objetivo principal y necesario para el desarrollo individual y social.

Este modelo educativo se impregna más formalmente en Colombia a partir de los años 90 con en el gobierno de Cesar Gaviria con la Apertura Económica,

7 Artículo 32, Ley 115 del 28 de febrero de 1994 
que da comienzo a un proceso de Globalización y no deja por fuera a la educación, asegura Martisela Bermudez Asprilla (2011). También explica que "Por ello, se inicia en las instituciones técnicas, especialmente en el SENA, un nuevo proceso de desarrollo curricular, basado en competencias que poco a poco ha ido llegando a las demás instituciones educativas de orden superior o de educación básica (s.p.).

\section{Mirada a una educación para el ocio}

¿Se podría entonces hablar de educación para el ocio? Luego de haber mencionado los inmensos debates alrededor del ocio y sus atributos como posible transformador social para el desarrollo humano, definitivamente debe hacer parte de la cultura del hombre pensarse en el espacio de tiempo dedicado a la introspección, a la meditación, al yo mismo, a la reflexión.

La escuela ha dejado de lado la búsqueda de la felicidad pensada de cada individuo, y ha decidido homogenizarla incrustando en la mente de sus educandos una idea de felicidad a partir del éxito, y ese éxito en nuestro contexto significa tener más que otros, resultado que solo se conseguirá si se es buen trabajador para lo cual puede servir el modelo de educación actual.

Y sin duda, tampoco es el interés de este trabajo rotular negativamente y de por vida a un sistema educativo, solo se considera necesario generar el interés por el escudriño de los comienzos de éste en Colombia para examinar las verdaderas intenciones del mismo en la educación de los colombianos, porque si se está educando para el trabajo, como trabajadores es entonces muy difícil asumir la importancia del tiempo del ocio en su vida cotidiana a diferencia de la percepción que ella tiene del tiempo de trabajo.

Gaspar se pregunta en su artículo: “¿quién nos hablará del valor humano del ocio, de la alegría de vivir, de la risa y del juego?” (p. 182). Verdaderamente, es un campo maravilloso de exploración para un investigador del ocio y la educación. 


\section{Contextualización del comienzo de mi labor académica con los trabajadores operarios}

Se compartirá con el lector un trabajo recién iniciado, una contextualización sin resultados que resaltan unos breves interrogantes.

Los trabajadores operarios que han abierto las puertas para que se pueda observar su cotidianidad laboral, han mostrado los intereses que tienen personas en sus condiciones y el estilo de vida que llevan. Sin duda han despertado un interés por esto de "los 15 minutos"- propuesta que se ha llevado a dos talleres de producción masiva y en cadena de screen y confección en dos localidades de Bogotá- a los que pueden acceder sin ningún tipo de control por parte de los empleadores.

Cada trabajador podrá acceder a 15 minutos todos los días- fuera de su hora habitual del almuerzo y otras actividades ya estipuladas dentro de la empresa- en el momento en que lo desee y para hacer lo que desee- siempre y cuando se encuentre dentro de las posibilidades de tiempo y espacio de la empresa- dentro o fuera del taller. El taller ha permitido la adecuación de espacios convencionales que permiten, si el trabajador lo desea, hacer uso de su tiempo de ocio allí dentro; espacios con televisión, música, juegos de mesa y demás. Cabe aclarar que éste trabajo se está realizando en talleres pequeños en donde convergen pocos trabajadores, lo que facilita de alguna manera una logística en los tiempos que cada uno escoge, porque en una industria con cientos de trabajadores difícilmente permitirían que cada uno de ellos se tome si quiera un minuto de manera desorganizada, pues el retraso en el trabajo de un solo operario, seguramente retrasará el trabajo de toda la producción por su característica de producción en cadena.

Aunque los 15 minutos de ocio que se han planteado no reemplazan un derecho negado durante siglos a este tipo de trabajadores, y seguramente nunca podrá ser viable en grandes industrias porque posiblemente desaparecerían, han servido para comenzar a generar la duda en ellos y en quién investiga, por esos tiempos. Se abre la posibilidad de pensar las razones por las cuales existe un sistema de trabajo como este en donde, para que funcione esta industria, debe trabajarse de manera masiva y en cadena- recordando la intensión fordiana-, en donde solo convergen trabajadores con ciertas características y que pareciera necesitar de trabajadores obedientes con muchas necesidades. ¿Es necesario este sistema laboral para el desarrollo de un país? .Si es así ¿̇de qué 
tipo de desarrollo se habla?; ¿tendrá que ver el consumo excesivo de las personas en la existencia y mantenencia de este modelo laboral?; ¿es posible que el modelo de educación influya en el sostenimiento de este sistema de trabajo?

Seguramente surgirán muchos más interrogantes en la continuación de este trabajo originado desde la perspectiva vivida del trabajo operario asalariado que grita necesidades de cambio.

\section{Referencias}

Archila, M. (2010). Cultura e identidad obrera: Colombia 1910-1945. Ed. CINEP

Caicedo, C. El trabajo flexible se impone a nivel mundial, pero en Colombia tiene sus detractores. Tomado de una de las secciones de la página web actualícese.com

Cuenca, 2009. Perspectivas actuales de la pedagogía del ocio y el tiempo libre. La pedagogía del ocio: nuevos desafíos. José Carlos Otero López (coord.). Editorial Axac.

Erizalde y Gomes (2010). Ocio y recreación en América Latina: conceptos, abordajes y posibilidades de resignificación. Revista de la Universidad Bolivariana, volumen 9, No 26, 2010, p. 19-40.

Etimología de Escuela. Recuperado de http://etimologias.dechile.net/?escuela

Etimología del obrero. Recuperado de http://etimologias.dechile.net/?obrero

Gawriszewski,B.(2003).Laluchacapitalistacontraelocio:lanecesidaddeunocioconsumista.

Revista digital Educación Física y Deportes, Buenos Aires, Año 9 Nro. 66, Noviembre de 2003. Recuperado de http://sociologiatl.wordpress.com/2011/03/17/la-lucha -capitalista-contra-el-ocio-la-necesidad-de-un-ocio-consumista/

http://lema.rae.es/drae/srv/search?id=lpUyJOhYWDXX20yTx

Ley 115 del 28 de febrero de 1994. Recuperado de http://www.mineducacion.gov. co/1621/articles-85906_archivo_pdf.pdf

Ministerio de Trabajo. Recuperado de http://www.mintrabajo.gov.co/preguntas-frecuentes/jornada-de-trabajo.html

Miranda, G. (2006). El tiempo libre y ocio reivindicado por los trabajadores. Revista de turismo y patrimonio Cultural Vol. 4 No. 3 Págs. 301-326

Rul-lán, G. (1997). Del ocio al negocio... y otra vez al ocio. Papers : revista de sociologia, 53, pp. 171-193.

Russell, B. (1932). Elogio de la ociosidad. Recuperado de http://alcoberro.info/pdf/ russell 3. pdf 
Tabares, José F. (2005). Cap. 1 El ocio y la recreación en América Latina. El ocio, el tiempo libre y la recreación en América Latina: problematizaciones y desafíos.

Tomado de la Revista virtual Contribuciones a las ciencias sociales; Grupo de investigación eumed.net. Artículo Algunas reflexiones sobre el currículo en la educación de MartiselaBermudez Asprilla. Véase: http://www.eumed.net/rev/ cccss/16/mba.html 